\title{
Prostate artery embolization: increasing self-referrals and awareness of treatment options
}

\author{
Himanshu Sharma ${ }^{1 *}$, Samuel Z. Maron ${ }^{1}$, Ardeshir R. Rastinehad ${ }^{2}$ and Aaron M. Fischman ${ }^{1}$
}

\section{Introduction}

Prostatic artery embolization (PAE) is a minimally invasive therapy performed as an elective outpatient procedure for lower urinary tract symptoms (LUTS) secondary to benign prostatic hyperplasia (BPH). Multiple studies have demonstrated the efficacy of PAE in reducing LUTS over the medium and long term (Pisco et al. 2016; Carnevale et al. 2020). PAE is transitioning from the research setting to implementation as a routine clinical procedure (Young and Golzarian 2019). The number of patients treated with PAE has grown in recent years, but the current literature has not well characterized awareness of PAE as a treatment option among patients. As PAE becomes more widespread, patients may not want to wait for a referral from a urologist or primary care physician, and instead self-refer to interventional radiology (IR) directly. IR practices in turn may need to engage with the patient community more directly and increase their online presence.

\section{Methods}

PAE cases from January 2015 until August 2020 at two hospitals in a tertiary academic health system were queried. Data from all consecutive PAE patients $(n=215)$ for any indication were included in this study. The patient referral source was collected by review of electronic medical records.

\section{Results}

The most common source of referral was urology $(n=104,48 \%)$, followed by self-referral $(n=64,30 \%)$,

\footnotetext{
* Correspondence: Himanshu.sharma@icahn.mssm.edu

${ }^{1}$ Icahn School of Medicine at Mount Sinai, Mount Sinai Hospital, 10029 New York, NY, USA

Full list of author information is available at the end of the article
}

internal medicine/primary care provider $(n=23,11 \%)$, inpatient consult $(n=14,6 \%)$, emergency department $(n=5,2 \%)$, external interventional radiology $(n=4,2 \%)$, and oncology $(n=1,1 \%)$. These results are summarized in Table 1.

Referral sources were calculated by year and results are summarized in Table 2 . While the sample sizes in 2015 and 2016 are small, the number of self-referred patients grew substantially from 6 patients in 2017 to 28 patients in 2019 (Fig. 1). There were 11 self-referrals in 2020 although the data only extends to August and is further limited by the institutional pause on elective procedures from March 16, 2020 to June 9, 2020 due to COVID-19. The proportion of self-referred patients also increased each year from the prior year. The proportion of self-referrals in 2015 was $0 \%(n=5)$, $20 \%$ in $2016(n=5), 21 \%$ in $2017(n=29), 29 \%$ in $2018(n=64), 35 \%$ in $2019(n=84)$, and $39 \%$ in $2020(n=28)$. Urology is the largest referral source, but the share of urology referrals has decreased from $62 \%$ to 2017 to $39 \%$ in 2020 . In 2020, the number of self-referrals was equal to urology referrals. Referrals from internal medicine/primary care provider increased from $7 \%$ of total referrals in 2017 to $12 \%$ in 2019. The distribution of referrals from urology, self-referral, primary care providers, and other sources between 2015 and 2020 is summarized in Fig. 1.

\section{Discussion}

The results of our retrospective review demonstrate the increasing popularity of PAE among patients.

\section{Springer Open}

(- The Author(s). 2021 Open Access This article is licensed under a Creative Commons Attribution 4.0 International License, which permits use, sharing, adaptation, distribution and reproduction in any medium or format, as long as you give appropriate credit to the original author(s) and the source, provide a link to the Creative Commons licence, and indicate if changes were made. The images or other third party material in this article are included in the article's Creative Commons licence, unless indicated otherwise in a credit line to the material. If material is not included in the article's Creative Commons licence and your intended use is not permitted by statutory regulation or exceeds the permitted use, you will need to obtain permission directly from the copyright holder. To view a copy of this licence, visit http://creativecommons.org/licenses/by/4.0/. 
Table 1 Total referrals by source 2015 - 2020

\begin{tabular}{|l|l|l}
\hline Referral Source & Patients & Percentage of Total \\
\hline Urology & 104 & $48 \%$ \\
\hline Self-referral & 64 & $30 \%$ \\
\hline Internal Medicine / Primary Care Provider & 23 & $11 \%$ \\
\hline Inpatient Consult & 14 & $7 \%$ \\
\hline Emergency Department & 5 & $2 \%$ \\
\hline External IR & 4 & $2 \%$ \\
\hline Oncology & 1 & $0 \%$ \\
\hline Total & 215 & $100 \%$ \\
\hline
\end{tabular}

Excluding small samples in 2015 and 2016, PAE volume increased by $121 \%$ from 2017 to 2018 and $31 \%$ from 2018 to 2019. Our findings also demonstrate that while urology is the largest referral source, the share of urology referrals has decreased from 2017 to 2020. An increasing number of patients self-refer for PAE. Between 2017 and 2020, self-referral has grown from $21 \%$ of PAE volume to $39 \%$.

Further study of patients who self-referred to determine the method through which they learned about PAE, such as word-of-mouth, advertising, media, or other sources, could allow IR practices to reach more patients directly. While our results indicate a growing appetite for PAE among our patient population, to our knowledge there have been no large studies assessing patient understanding of PAE. As the generalizability of the present study is limited by its single-system design, future work examining PAE referral and volume at the regional and national level will be useful in assessing broader patient knowledge of and access to PAE. Patients have a wide range of options for treatment for LUTS secondary to $\mathrm{BPH}$, ranging from conservative medical management, to minimally invasive options including
PAE, to more invasive procedures such as transurethral prostate resection, Urolift, Rezum, and prostatectomy. Greater understanding of the patients who self-referred to PAE may help interventional radiologists assess the methods by which they can educate $\mathrm{BPH}$ patients about minimally invasive alternatives.

In addition to further study of patient knowledge of PAE, assessment of awareness of PAE among primary care providers could be useful. Internal medicine/primary care provider referrals for PAE grew from 2 to 2017 to 10 in 2019, but comprised a smaller share of total referrals in 2019 (12\%) than urology (51\%) and self-referrals (33\%). Educating internal medicine, geriatrics, and family medicine departments on PAE as a treatment option for $\mathrm{BPH}$ could present an opportunity to reach more patients and cultivate another referral source.

As seen with the relatively low penetration of uterine fibroid embolization compared to hysterectomy, patient awareness of IR procedures can be concerningly low despite establishment of safety and efficacy (Makris et al. 2020). Further study of public awareness of PAE is crucial in spreading access to all patients who might benefit from the procedure.

Table 2 Referral sources by year from 2015 - 2020

\begin{tabular}{|l|r|r|r|r|r|r|}
\hline Referral Source & $\mathbf{2 0 1 5}$ & $\mathbf{2 0 1 6}$ & $\mathbf{2 0 1 7}$ & $\mathbf{2 0 1 8}$ & $\mathbf{2 0 1 9}$ & $\mathbf{2 0 2 0}$ \\
\hline Urology & 2 & 2 & 18 & 28 & 43 & 11 \\
\hline Self-Referral & 0 & 1 & 6 & 18 & 28 & 11 \\
\hline Internal Medicine / Primary Care Provider & 0 & 1 & 2 & 3 & 8 & 10 \\
\hline Other (1) & 3 & 1 & 3 & 10 & 3 & 4 \\
\hline Total & 5 & 5 & 29 & 64 & 84 & 28 \\
\hline
\end{tabular}

(1) Other includes Inpatient Consult, Emergency Department, External IR, and Oncology 


\section{Origin of PAE Referrals 2015 - 2020}

90

80

70

60

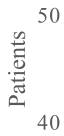

30

20

10

0

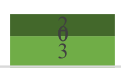

2015

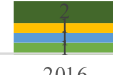

2017

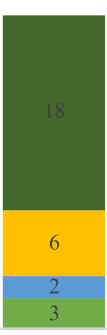

2016

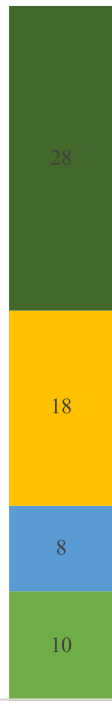

2018

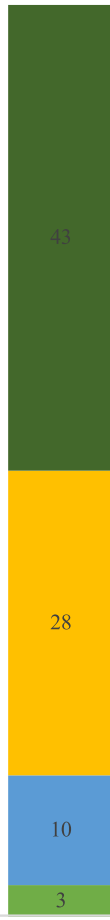

2019

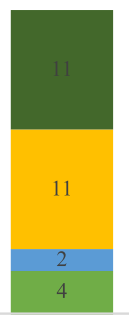

$2020(2)$

-Other (1) $\quad$ Internal Medicine/PCP $\quad$ Self $\quad$ urology

1. Other includes Emergency Department, Inpatient Consult, IR, and Oncology

2. 2020 results extend to August 2020 and reflect an institutional pause on elective procedures from March 16 - June 92020 due to COVID-19 Fig. 1

\section{Conclusions}

These preliminary findings suggest that urology continues to be the most prevalent source of PAE referrals, with an increasing proportion of selfreferrals. The growing number of self-referrals suggests an increasing awareness of PAE as a treatment option in the patient community. Further study of patient awareness and understanding of PAE could be useful in increasing access to the procedure.

\section{Abbreviations}

PAE: Prostate Artery Embolization; LUTS: Lower Urinary Tract Symptoms; BPH: Benign Prostatic Hyperplasia; IR: Interventional Radiology

\section{Acknowledgements}

None.

\section{Authors' contributions}

HS and SM analyzed the data and wrote the manuscript. The authors read and approved the final manuscript.

\section{Funding}

No outside funding or grants were received to assist in completion of this study.

\section{Availability of data and materials}

The datasets generated and/or analyzed during the current study are not publicly available due to protected patient health information but are available from the corresponding author on reasonable request.

\section{Declarations}

Ethics approval and consent to participate

Institutional Review Board (IRB) approval was obtained for this study.

Consent for publication

Not applicable.

\section{Competing interests}

AM Fischman, MD is a paid consultant for Terumo and Boston Scientific; on the advisory board for Terumo, Embolx, and Boston Scientific; a speaker for Terumo and Boston Scientific; provided research support from Boston

Scientific; has a royalty agreement with Merit Medical; and is an investor in Adient Medical.

None of the other authors have financial disclosures. 


\section{Author details}

'Icahn School of Medicine at Mount Sinai, Mount Sinai Hospital, 10029 New York, NY, USA. ${ }^{2}$ The Smith Institute for Urology, Northwell Health, Lenox Hill Hospital, 245 E 54th St., 320 Central Park West, Apt 2A, NY 10022 New York, USA.

Received: 3 April 2021 Accepted: 30 July 2021

Published online: 23 August 2021

\section{References}

Carnevale FC, Moreira AM, de Assis AM et al (2020) Prostatic Artery Embolization for the Treatment of Lower Urinary Tract Symptoms Due to Benign Prostatic Hyperplasia: 10 Years' Experience. Radiology 296(2):444-451

Makris GC, Butt S, Sabharwal T (2020) Unnecessary hysterectomies and our role as interventional radiology community. CVIR Endovasc 3(1):46

Pisco JM, Bilhim T, Pinheiro LC et al (2016) Medium- and Long-Term Outcome of Prostate Artery Embolization for Patients with Benign Prostatic Hyperplasia: Results in 630 Patients. J Vasc Interv Radiol 27(8):1115-1122

Young S, Golzarian J (2019) Prostate embolization: patient selection, clinical management and results. CVIR Endovasc 2(1):7

\section{Publisher's Note}

Springer Nature remains neutral with regard to jurisdictional claims in published maps and institutional affiliations.

\section{Submit your manuscript to a SpringerOpen ${ }^{\circ}$ journal and benefit from:}

- Convenient online submission

Rigorous peer review

- Open access: articles freely available online

High visibility within the field

- Retaining the copyright to your article 